\title{
Demand Characteristics of Electricity in Residential Sector of Kathmandu Valley
}

\author{
Utsav Shree Rajbhandari ${ }^{1}$ *, Laxman Poudel ${ }^{1}$, Nawraj Bhattarai ${ }^{1}$ \\ ${ }^{1}$ Department of Mechanical Engineering, Pulchowk Campus, Institute of Engineering, Tribhuvan University, Nepal \\ Corresponding Email: utsavshree@hotmail.com
}

\begin{abstract}
:
Planning for electricity demand is a vital as the characteristics of different electricity generation systems vary temporally - both hourly in a day as well as seasonally in a year. Thus, this study focuses on evaluating the demand characteristic of electricity in residential sector within urban boundaries of three districts in Kathmandu Valley. It has addressed variations in demand in form of load curve based on hourly peak demand during a day. The demand characteristics have been affected in recent years are primarily influenced by two factors - the trade debacle in 2015 and the end of load-shedding. A typical family with owned household would have highest demand with loads spread over various time of the day. While the one in rented family would have least demand level with most characteristic peaks. But in overall, there are peculiar morning and evening peaks, in addition to small early morning peak. The current technology interventions and electricity consumption pattern with reference in earlier years depicts the change in energy technology preference. The reduction in daily demand pattern as well as total electricity demand are majorly due to replacement of older technologies with more efficient appliances as well as reduced use of inverters for battery charging. Thus, it can be said that a stringent condition can enforce people to change to efficient technologies as well as proper supply can reduce unnecessary demand in battery charging. On other hand, similar trend, and hence the increase in electricity demand, can be anticipated in other flourishing urban areas of the country. Additionally, it is beneficial to have the demand characteristics of each sector separately - which can be useful to design the decentralized systems for specific sector.
\end{abstract}

Keywords: Urban, Nepal, Electricity, Statistical Prediction, Load Curve

\section{Introduction}

Electricity is versatile form of energy - it can be easily transformed into any form of energy in most of the cases. Thus, electricity has been the major demanded form of energy, not only in stationary use, but also in for mobile form of technologies - like in transportation. The development of countries is scaled by consumption of energy. Thus the sustainable development goals has focused on access to modern energy to every households [1], while world bank has set 5-tier targets based on electricity consumption per household [2].

The load profile development has been used as an efficient, organized and systematic tool for energy planning design and load management [3]. Proper analysis and subsequent implications of accurate load profiles can not only be used for balancing load for increasing system stability and reliability but also design and develop the new supply systems and strategies for load diversification such as by grid connected solar PVs.

\subsection{National context}

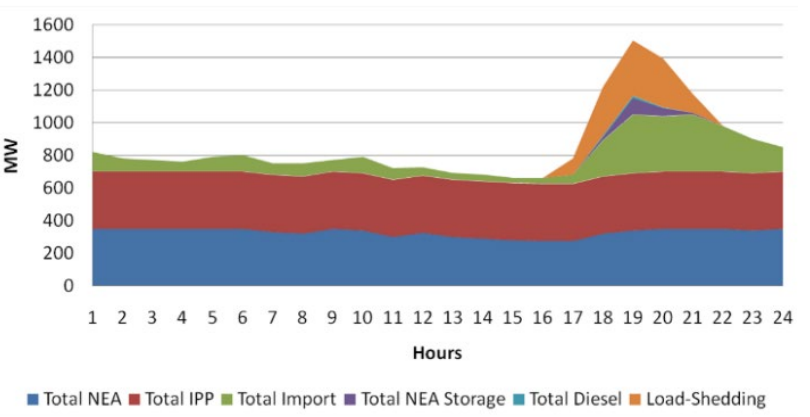

Figure 1: System load curve of Nepal in 2017 peak day

The electricity demand in Nepal has been facing deficit for past decade. Nepal has faced load shedding due to supply deficit. Nepal has been importing electricity from India for a long time now and in 2017 alone, Nepal Electricity Authority (NEA) purchased 2,175 GWh of electricity in 2017 which is $35 \%$ of total demand [4]. According to NEA's report, it is expected to reach 2,580 GWh in 2018 which totals to $37 \%$. Figure 1 shows a daily load curve for Nepal in 2017. It can be seen that there is an abrupt peak in the evening. Five years back, two prominent peaks could be observed [5]. The demand in morning peak has not decreased. But demand in other time 
have increased. The current smoothing in load curve could be attributed to two main factors - first the bloom of commercial institutions and secondly load distribution in industries to off peak hours.

\subsection{Kathmandu Valley}

Kathmandu Valley - that constitute three districts is the most densely populated area in one hand [6] and fastest growing urban agglomerate in Nepal [7]. Thus, not only the demand for electricity is increasing in whole nation, but in Kathmandu valley as well. Kathmandu valley is a major focal point in terms of electricity load management. From Figure 2 it can be seen that in 2017, more than one fourth of peak demand can be attributed to Kathmandu valley alone [8]. It is also noticeable that the load pattern of Nepal and Kathmandu looks very similar. Thus, it can be seen that the demand pattern of Kathmandu valley highly determines the load pattern of whole nation.

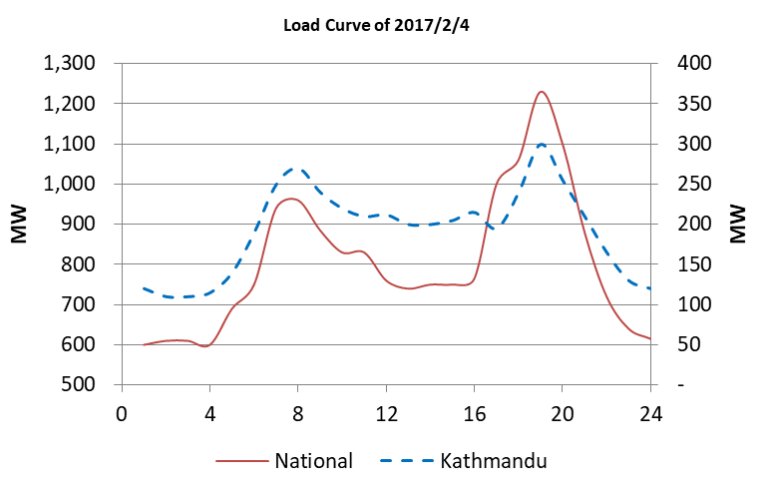

Figure 2: Daily load curves for supply and demand of Nepal and Kathmandu in 2017

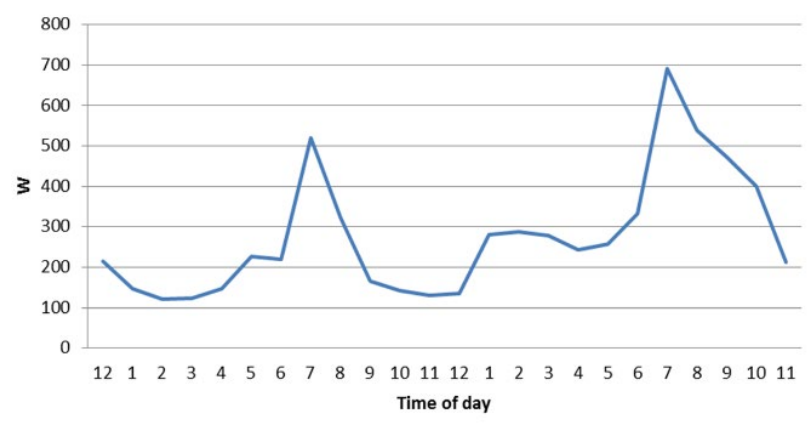

Figure 3: Demand curve of a household in Kathmandu Valley in 2013

Now taking one more step into root level of demand side, if we look at the pattern of residential sector as studied by Rajbhandari et al. presented in Figure 3 [9] and compare it to that of Figure 2 we can see another striking similarity in the pattern. In addition to that, an estimation derived by Pudasaini and Bhattarai showed that the residential peak demand of Kathmandu valley was about 250 MW in 2015
[10]. Thus, it can be deduced that the peak load pattern of the valley is primarily determined by residential sector.

The objective of this paper is to develop realistic electricity profiles for local resident of Kathmandu valley. The load profiles for the domestic customers of Kathmandu Valley are generated through statistical prediction put upon by Rahman and Arnob [11]. It is aimed at increasing knowledge and understanding of load usage of urban context.

\section{Methodology}

Figure 4 represents the general methodological approach from developing the load profiles of residential sector through consumer survey. It is important to have as much comprehensive and detailed electricity usage data for accurate analysis if demand. Bottom-up approach is applied in this study - which builds up the total load for each type of house, considering every major appliance, in a statistical average manner. The number of statistically significant sample size was calculated using methodology given by Krejcie and Morgan [12]. With confidence level of $95 \%$ and degree of accuracy $10 \%$, a total of 96 household samples were taken.



Figure 4: Methodological flowchart

The questionnaire would give appliance saturation that represents usage of each appliances and hourly usage of each appliance. In addition to that, it would also give information on frequency of use and nominal wattage. The analysis was done and the load profiles are plotted in Excel on an hourly basis to generate daily electrical load profiles for each of the household types. Microsoft Excel has been used to plot the profile due to its acceptance as powerful and widely used Spreadsheet software developed by Microsoft Corporation. 


\subsection{Household categories}

The pattern of electricity demand could be affected by various factors ranging from income, family size, house built up and so on. For this study, four family types have been considered based on categorical differentiation given by Michalik et al. [13].

Table 1: Household Categories

\begin{tabular}{|l|l|}
\hline $\begin{array}{l}\text { Cate- } \\
\text { gory }\end{array}$ & Description \\
\hline $\mathrm{H}_{1}$ & $\begin{array}{l}\text { At least one adult at home, children at home or at } \\
\text { school (typical family with small children, working } \\
\text { father, mother at home) }\end{array}$ \\
\hline $\mathrm{H}_{2}$ & $\begin{array}{l}\text { Two or more working adults, children at school } \\
\text { and/or university during business hours (both } \\
\text { parents have jobs outside the household) }\end{array}$ \\
\hline $\mathrm{H}_{3}$ & $\begin{array}{l}\text { One, two or three working adults, no children at } \\
\text { home (single person, working couple without } \\
\text { children, or a household shared by a few young } \\
\text { working persons) }\end{array}$ \\
\hline $\mathrm{H}_{4}$ & $\begin{array}{l}\text { One or two adults, at least one at home during } \\
\text { business hours, no children at home (couple/single } \\
\text { pensioner, couple/single unemployed }\end{array}$ \\
\hline
\end{tabular}

\subsection{Electric appliances saturation and use}

The findings of the survey only represent the number of users of each appliance regardless of ownership. It also includes the nominal power rating of each appliance commonly used and their working frequency each day as well as weekly to consider the variability of usage in monthly or annual basis. For refrigerator, which is usually left connected to load, it is taken that it runs for 12 minutes with frequency of 40 times per day [14]. In addition to these, following assumptions were made:

- Differentiation between weekdays and weekends is not considered,

- Different daily load profiles are not simulated; rather single day is simulated. The mean daily use frequency factor is assumed to incorporate the dynamics.

- Use of an appliance is affected by users' behaviors. However, it is very difficult to model such stochastic behavior. The average usage time for an appliance is assumed to cover up that.

- The variations in economic conditions, influencing the appliance type and usage patterns are not considered.

The list of appliances, there usage saturation along with their nominal wattage and usage details are given in Annex. These data represent average of all four household categories.

\subsection{Time of use probability profile}

The time of use probability profiles gives probability of the particular activity being commenced or undertaken as a function of time of day. The probability profiles represent the probability of a household carrying out a specified activity during a 24 hour period. Rahman and Arnob used this method to develop load profile for Dhaka [11]. The relative probability of each appliance use is given by

$$
P_{R}=\frac{N_{x}}{N_{t}}
$$

Where $P_{R}$ is the relative probability, $N_{x}$ is the number of times an event $\mathrm{x}$ occurred, and $\mathrm{N}_{t}$ is the total number of trials. These data are obtained from the questionnaire survey and the probability of appliance use was developed using equation (1), which was used generate load profiles. The probability of each appliance being used in each hour are given in Annex.

\section{$3 \quad$ Findings and Discussions}

Figure 5 shows the load profiles for four different type of households considered for study. The household type $\mathrm{H}_{1}$, which represents a typical household - especially with more than two generations residing in a house - shows two peculiar peaks at morning and evening between 7 and 8 in both morning and evening. A tiny peak at around 5 am represents the use of appliance by early risers like students or elderlies.

The household type $\mathrm{H}_{2}$ - which mostly represents small family with parents and children, shows similar pattern of $\mathrm{H}_{1}$ however being smaller size as well as very few activities at business hours, the maximum demands at each hour are lower than that of $\mathrm{H}_{1}$.

The household type $\mathrm{H}_{3}$ - which generally represents a group of adults such as working people or students in rents shows a very different pattern. There are two peaks in morning. The first peaks are due to early rising students while the second rise are majorly due to working adults or day scholars. The evening peak is at as other earlier families but not as wide spread as in category with majorly owned house. In addition to that, the total electricity demand is also much lower in this category due to lower saturation of appliances.

The household type $\mathrm{H}_{4}$ - that majorly includes a family with very less chance of early risers shows similar pattern to that of type $\mathrm{H}_{1}$ but the early morning peak is not as prominent as in prior types. There is another small peak later in daytime near around when cooking or heating of food is generally required. 


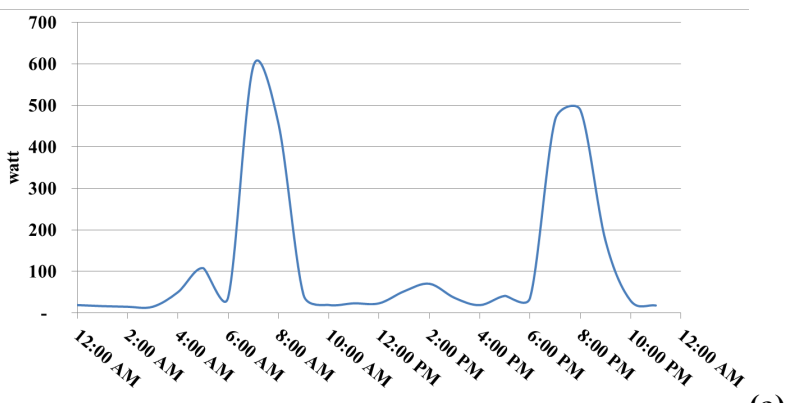

(a)
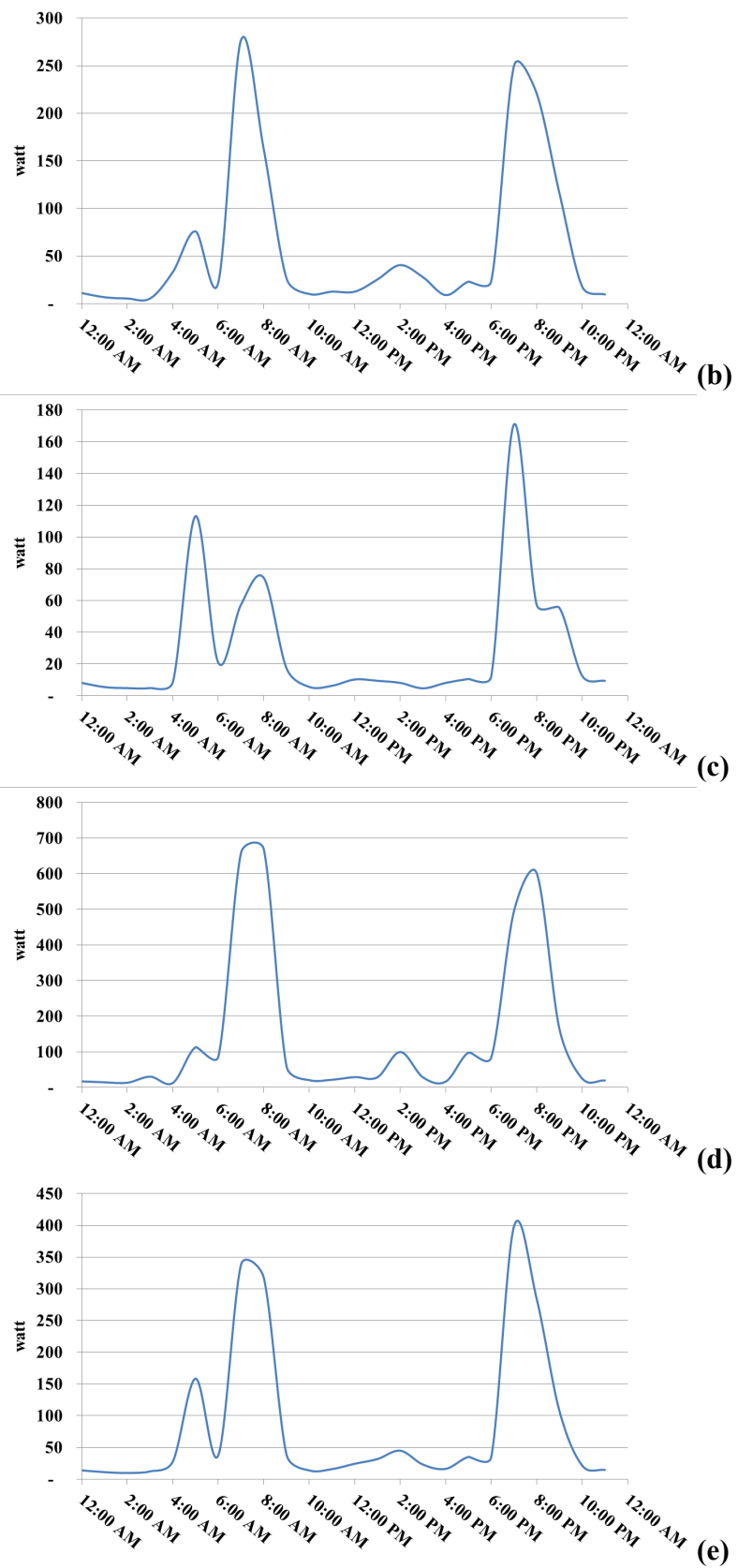

Figure 5: Load profile for different households (a) type $H_{1}$ (b) type $\mathrm{H}_{2}$ (c) type $\mathrm{H}_{3}$ (d) type $\mathrm{H}_{4}$ and (e) cumulative average of types of households.

Thus, it can be seen that the behavioral types of each household can differentiate the demand profile as well as overall demand of each type of family.
The overall load pattern in Figure 5(e) when compared to Figure 2 and Figure 3 shows similarities. Thus, the outcomes of this study can represent the load pattern of the urban household in Kathmandu valley. Going further into the total demand, the average electricity consumption per annum totals to around $182 \mathrm{kWh}$ per capita per annum. This is in between to the mark of $208 \mathrm{kWh}$ per capita in 2013 [15] and $140 \mathrm{kWh}$ in 2016 [16-18]. The difference in the annual consumption arises from few assumptions and limitations of the study. Firstly, it is hugely affected by randomness of samples taken. Secondly, the former study was limited within only five municipalities of the valley in that time. Secondly, the study does not consider winter load like room heater or added water heating or cooking time. Also, in course of time, the users of CRT TV, CFL and tube lights, desktops have drastically reduced and got replaced by efficient LED TV, LED lights and laptops. In addition to that, due to removal of loadshedding the use of inverters for battery charging has also reduced. The effect of these can also be seen when compared to Figure 3. One of the main parts of electricity demand in 2103 was other uses, which included inverters as well as larger number of less efficient appliances [9].

With these findings following insights can be deduced:

- The pattern and total demand of the household can be affected by the type of household composition. The more the members with some economically inactive member have higher electricity demand.

- The peculiar morning an evening peaks are easily visible during period of $7 \mathrm{AM}$ to $8 \mathrm{AM}$ in the morning and evening peak at $7 \mathrm{PM}$ to $8 \mathrm{PM}$. However, the demand pattern can spread to varying duration usually with household with someone at home.

- The early morning peaks can be seen in households with early risers.

- The saturation of appliances is also dependent of family type - usually the ownership.

- The overall demand in electricity might have reduced due to penetration of efficient appliances. But the total demand in the valley remains high due to increasing number of populations.

\section{Conclusion}

The objective of this study was to generate load profile of electricity demand of residential sector in Kathmandu valley for various household types. The households were classified into four types my composition of family members. Bottom-up approach was applied to analyze appliance usage profile. 
The study considers typical electrical appliances, its relative saturation depending on the household type, the power rating and the utilization pattern in terms of frequency of operation, probability of being on at particular hour. The overall load pattern and total demand was checked against the load profile of Kathmandu valley and total electricity consumption.

The current technology interventions and electricity consumption pattern with reference in earlier years depicts the change in energy technology preference, which has been brought about by accessibility to technologies reducing prices and also some externalities. The reduction in daily demand pattern as well as total electricity demand are majorly due to replacement of older technologies with more efficient appliances as well as reduced use of inverters for battery charging. Thus, it can be said that a stringent polices can enforce people to change to efficient technologies as well as proper supply can reduce unnecessary demand in battery charging. On other hand, taking similar trend of the valley, the increase in electricity demand can be anticipated in other flourishing urban areas of the country as well.

The more detailed modeling of electricity usage pattern could help in future research for not only demand side management but also operation and design of supply side such as solar PV and smart grid systems.

\section{References}

[1] UNDESA, "Sustainable Development Goal 7," [Online]. Available: https://sustainabledevelopment.un.org/sdg7. [Accessed 2018].

[2] M. Bhatia and N. Angelou, "Beyond Connections : Energy Access Redefined," World Bank, Washington, DC., 2015.

[3] Union of the Electricity Industry, "Metering Load, Metering Load Profiles and Settlement in Deregulated Markets," 2000.

[4] NEA, "Annual Report 2018," Nepal Electricty Authority, Kathmandu, Nepal, 2018.

[5] NEA, "A Year in Review, Fiscal Year 2011/12," Kathmandu Nepal, 2012.

[6] CBS, "National Population and Housing Census 2011," Central Bureau of Statistic, National Planning Commission Secretariat, Government of Nepal, Kathmandu, 2012.

[7] E. Muzzini and G. Aparicio, Urban Growth and Spatial Transition in Nepal: An Initial Assessment, World Bank Publications, 2013.
[8] NEA, "Load curve complied by Bikal Adhikari," Nepal Electricity Authority, Kathmandu, Nepal, 2018.

[9] U. S. Rajbhandari, L. Poudel, N. Bhattrai and S. R. Shakya, "Development of Demand Load Curve for Electricity Consumption of the Residential Sector in Kathmandu Valley," in 1st TU-NUAA Joint Academic Workshop, Kathmandu, Nepal, 2018.

[10] N. Pudasaini and B. Nawraj, "Impact Study of Decentralised PV Generation on Peak Load Reduction in Residential Sector of Kathmandu Valley," in IOEGraduate Conference 2015, Lalitpur, Nepal, 2015.

[11] A. Rahman and S. I. C. Arnob, "Developing Load Profile for Domestic Customers of Dhaka City through Statistical Prediction," in 2016 3rd International Conference on Electrical Engineering and Information Communication Technology (ICEEICT), Dhaka, Bangladesh, 2016.

[12] R. V. Krejcie and D. W. Morgan, "Determining Sample Size for Research," Educational and Psychological Measurement, pp. 607-610, 1970.

[13] G. Michalik, M. E. Khan, W. J. Bonwlck and W. Mielczarski, "Structural Modelling Of Energy Demand In The Residential Sector: 1. Development Of Structural Models," pp. 937-947, 1997.

[14] L. Chuan and A. Ukil, "Modeling and Validation of Electrical Load Profiling in Residential Buildings in Singapore," IEEE Transactions on Power Systems, vol. 30, no. 5, pp. 2800 - 2809, 2014.

[15] U. S. Rajbhandari and A. M. Nakarmi, "Energy Consumption and Scenario Analysis of Residential Sector Using Optimization Model - A Case of Kathmandu Valley," in Proceedings of IOE Graduate Conference, Kathmandu, Nepal, 2014.

[16] AEPC, "District Climate and Energy Plan - Kathmandu District," Alternative Energy Promotion Center, Lalitpur, Nepal, 2017.

[17] AEPC, "District Climate and Energy Plan - Lalitpur District," Alternative Energy Promotion Center, Lalitpur, Nepal, 2017.

[18] AEPC, "District Climate and Energy Plan - Bhaktapur District," Alternative Energy Promotion Center, Lalitpur, Nepal, 2017.

\section{Appendix}


Table 2: The questionnaire (Lifestyle Matrix)

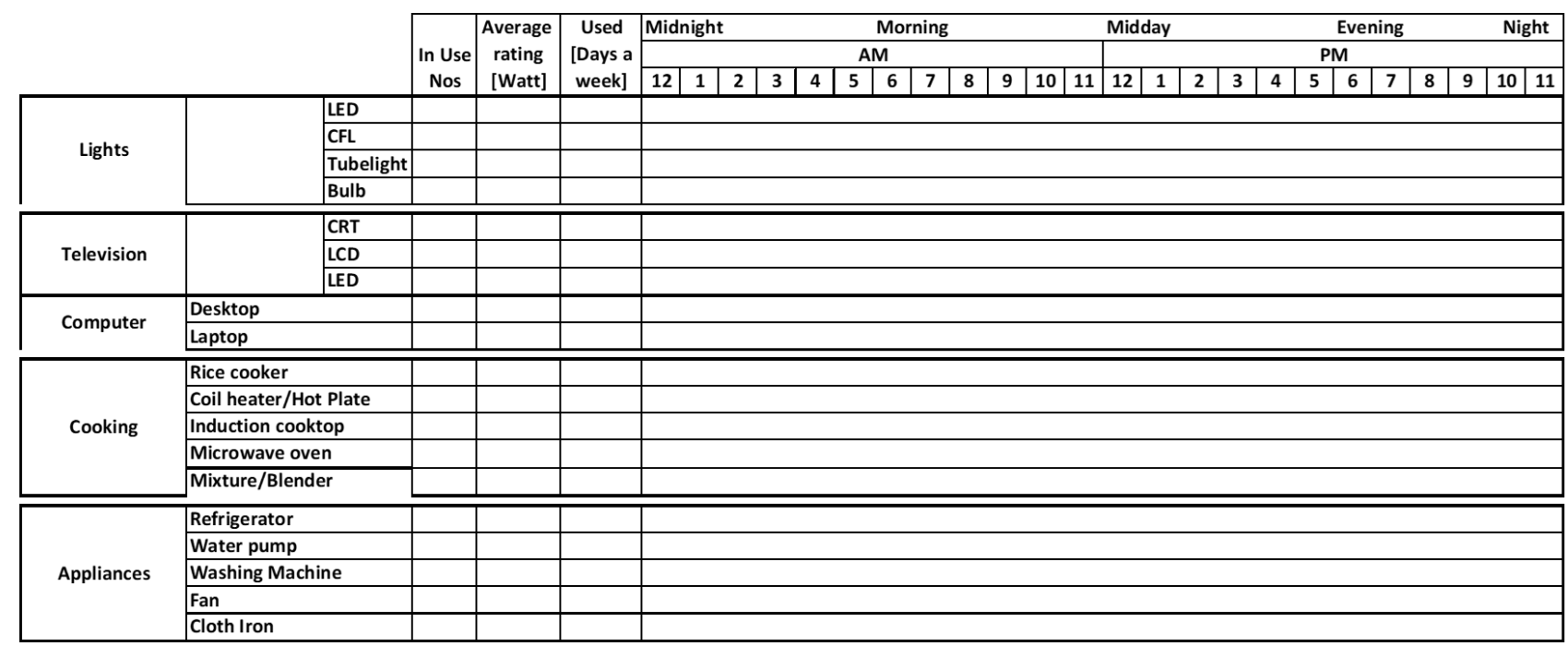

Table 3: Residential appliances: list, saturation level, nominal wattage average daily use frequency, and time per use.

\begin{tabular}{|l|l|l|l|l|l|l|}
\hline Appliances & Saturation & $\begin{array}{l}\text { Nominal } \\
\text { wattage }\end{array}$ & $\begin{array}{l}\text { Average days } \\
\text { of use per week }\end{array}$ & $\begin{array}{l}\text { Averaged times } \\
\text { of use per day }\end{array}$ & $\begin{array}{l}\text { Mean daily } \\
\text { use frequency }\end{array}$ & $\begin{array}{l}\text { Average time } \\
\text { per usage (hours) }\end{array}$ \\
\hline LED & 0.65 & 10 & 7 & 2 & 2.00 & 3.00 \\
\hline CFL & 0.61 & 20 & 7 & 2 & 2.00 & 3.00 \\
\hline TFT & 0.33 & 40 & 7 & 2 & 2.00 & 3.00 \\
\hline Bulb & 0.06 & 25 & 7 & 1.75 & 1.75 & 3.00 \\
\hline Rice cooker & 0.51 & 500 & 7 & 2 & 2.00 & 0.50 \\
\hline Coil heater/hot plate & 0.03 & 1000 & 0.25 & 0.25 & 0.01 & 0.50 \\
\hline Induction Cooktop & 0.48 & 2000 & 5.5 & 1.75 & 1.38 & 0.17 \\
\hline Microwave & 0.32 & 1000 & 4.75 & 1.5 & 1.02 & 0.08 \\
\hline Mixer blender & 0.61 & 400 & 2.75 & 1 & 0.39 & 0.02 \\
\hline Refrigerator & 0.56 & 200 & 7 & 40.5 & 40.50 & 0.20 \\
\hline Water pump & 0.69 & 750 & 2.25 & 1 & 0.32 & 1.00 \\
\hline Washing Machine & 0.43 & 300 & 1 & 1 & 0.14 & 0.50 \\
\hline Cloth Iron & 0.54 & 1000 & 1.75 & 1 & 0.25 & 0.10 \\
\hline Fan & 0.69 & 40 & 4.5 & 1 & 0.64 & 2.00 \\
\hline TV - CRT & 0.48 & 120 & 6.25 & 1.25 & 1.12 & 2.00 \\
\hline TV - LCD & 0.16 & 150 & 6.25 & 1 & 0.89 & 2.00 \\
\hline TV - LED & 0.54 & 30 & 6.75 & 1.25 & 1.21 & 2.00 \\
\hline Desktop & 0.15 & 150 & 3.25 & 1 & 0.46 & 2.00 \\
\hline Laptop & 0.59 & 50 & 6.75 & 1 & 0.96 & 4.00 \\
\hline
\end{tabular}


Table 4: Time of use probability profile for household $\mathrm{H}_{1}$

\begin{tabular}{|c|c|c|c|c|c|c|c|c|c|c|c|c|}
\hline & \multicolumn{12}{|c|}{ Time of day } \\
\hline & \multicolumn{12}{|c|}{$\mathbf{A M}$} \\
\hline & 12 & 1 & 2 & 3 & 4 & 5 & 6 & 7 & 8 & 9 & 10 & 11 \\
\hline LED & 0.0491 & 0.0119 & - & - & 0.0138 & 0.0459 & 0.0459 & 0.0278 & - & - & - & - \\
\hline CFL & 0.0491 & 0.0119 & - & - & 0.0138 & 0.0459 & 0.0459 & 0.0278 & - & - & - & - \\
\hline TFT & 0.0491 & 0.0119 & - & - & 0.0138 & 0.0459 & 0.0459 & 0.0278 & - & - & - & - \\
\hline Bulb & 0.0491 & 0.0119 & - & - & 0.0138 & 0.0459 & 0.0459 & 0.0278 & - & - & - & - \\
\hline Rice cooker & - & - & - & - & - & - & - & 0.4000 & 0.1000 & - & - & - \\
\hline Coil heater/hot plate & - & - & - & - & - & - & - & 0.2500 & 0.2500 & - & - & - \\
\hline Induction Cooktop & - & - & - & - & - & - & - & 0.2500 & 0.2500 & - & - & - \\
\hline Microwave & - & - & - & - & - & 0.0909 & - & 0.1818 & 0.1818 & - & - & - \\
\hline Mixer blender & - & - & - & - & - & - & - & 0.4615 & 0.1846 & 0.0769 & - & - \\
\hline Refrigerator & 0.0417 & 0.0417 & 0.0417 & 0.0417 & 0.0417 & 0.0417 & 0.0417 & 0.0417 & 0.0417 & 0.0417 & 0.0417 & 0.0417 \\
\hline Water pump & - & - & - & - & 0.1667 & 0.3333 & - & 0.0833 & 0.0833 & 0.0833 & - & - \\
\hline Washing Machine & - & - & - & - & - & - & - & - & - & 0.0645 & 0.1613 & 0.3226 \\
\hline Cloth Iron & - & - & - & - & - & - & 0.0800 & 0.2000 & 0.1200 & - & - & - \\
\hline Fan & 0.0339 & - & - & - & - & - & - & - & - & - & - & - \\
\hline TV - CRT & - & - & - & - & - & - & - & 0.1429 & 0.1429 & - & - & - \\
\hline TV - LCD & - & - & - & - & - & - & - & 0.0588 & 0.0588 & 0.0588 & - & - \\
\hline TV - LED & 0.0250 & - & - & - & 0.0125 & 0.0125 & 0.0375 & 0.0375 & 0.0375 & 0.0125 & 0.0125 & - \\
\hline Desktop & - & - & - & - & - & - & - & - & - & - & - & - \\
\hline Laptop & 0.0357 & 0.0357 & - & - & - & 0.0714 & 0.0714 & 0.0714 & 0.0714 & - & - & - \\
\hline
\end{tabular}

\begin{tabular}{|c|c|c|c|c|c|c|c|c|c|c|c|c|}
\hline & \multicolumn{12}{|c|}{ Time of day } \\
\hline & \multicolumn{12}{|c|}{ PM } \\
\hline & 12 & 1 & 2 & 3 & 4 & 5 & 6 & 7 & 8 & 9 & 10 & 11 \\
\hline LED & - & - & - & - & - & 0.0388 & 0.0558 & 0.1625 & 0.1741 & 0.1920 & 0.1489 & 0.0335 \\
\hline CFL & - & - & - & - & - & 0.0388 & 0.0558 & 0.1625 & 0.1741 & 0.1920 & 0.1489 & 0.0335 \\
\hline TFT & - & - & - & - & - & 0.0388 & 0.0558 & 0.1625 & 0.1741 & 0.1920 & 0.1489 & 0.0335 \\
\hline Bulb & - & - & - & - & - & 0.0388 & 0.0558 & 0.1625 & 0.1741 & 0.1920 & 0.1489 & 0.0335 \\
\hline Rice cooker & - & - & - & - & - & - & - & 0.4000 & 0.1000 & - & - & - \\
\hline Coil heater/hot plate & - & - & - & - & - & - & - & 0.2500 & 0.2500 & - & - & - \\
\hline Induction Cooktop & - & - & - & - & - & - & - & 0.2500 & 0.2500 & - & - & - \\
\hline Microwave & - & - & 0.0909 & - & - & 0.0909 & - & - & 0.1818 & 0.1818 & - & - \\
\hline Mixer blender & - & - & - & - & - & - & - & 0.0769 & 0.2000 & - & - & - \\
\hline Refrigerator & 0.0417 & 0.0417 & 0.0417 & 0.0417 & 0.0417 & 0.0417 & 0.0417 & 0.0417 & 0.0417 & 0.0417 & 0.0417 & 0.0417 \\
\hline Water pump & - & 0.0833 & 0.0833 & 0.0833 & - & - & - & - & - & - & - & - \\
\hline Washing Machine & 0.3226 & 0.1290 & - & - & - & - & - & - & - & - & - & - \\
\hline Cloth Iron & - & - & - & - & - & - & - & - & 0.2000 & 0.4000 & - & - \\
\hline Fan & - & 0.1017 & 0.1017 & 0.1017 & 0.1017 & 0.1017 & 0.1186 & 0.0847 & 0.0847 & 0.0847 & 0.0847 & - \\
\hline TV - CRT & - & 0.1429 & 0.1429 & - & - & - & 0.1429 & 0.1429 & 0.1429 & - & - & - \\
\hline TV - LCD & - & - & - & - & - & - & 0.0588 & 0.1765 & 0.1765 & 0.1765 & 0.1176 & - \\
\hline TV - LED & - & 0.0750 & 0.0750 & 0.0750 & 0.0500 & 0.0625 & 0.0875 & 0.1000 & 0.1000 & 0.1000 & 0.0625 & 0.0250 \\
\hline Desktop & - & - & - & - & - & - & - & 0.1429 & 0.5714 & 0.2857 & - & - \\
\hline Laptop & - & - & 0.0179 & 0.0179 & 0.0179 & 0.0179 & 0.0179 & 0.1250 & 0.1250 & 0.1250 & 0.1250 & 0.0536 \\
\hline
\end{tabular}


Table 5: Time of use probability profile for household $\mathrm{H}_{2}$

\begin{tabular}{|c|c|c|c|c|c|c|c|c|c|c|c|c|}
\hline & \multicolumn{12}{|c|}{ Time of day } \\
\hline & \multicolumn{12}{|c|}{$\mathbf{A M}$} \\
\hline & 12 & 1 & 2 & 3 & 4 & 5 & 6 & 7 & 8 & 9 & 10 & 11 \\
\hline LED & 0.0655 & 0.0159 & - & - & 0.0184 & 0.0555 & 0.0555 & 0.0371 & - & - & - & - \\
\hline CFL & 0.0655 & 0.0159 & - & - & 0.0184 & 0.0555 & 0.0555 & 0.0371 & - & - & - & - \\
\hline TFT & 0.0655 & 0.0159 & - & - & 0.0184 & 0.0555 & 0.0555 & 0.0371 & - & - & - & - \\
\hline Bulb & 0.0655 & 0.0159 & - & - & 0.0184 & 0.0555 & 0.0555 & 0.0371 & - & - & - & - \\
\hline Rice cooker & - & - & - & - & - & - & - & 0.4000 & 0.1000 & - & - & - \\
\hline Coil heater/hot plate & - & - & - & - & - & - & - & 0.2500 & 0.2500 & - & - & - \\
\hline Induction Cooktop & - & - & - & - & - & - & - & 0.2500 & 0.2500 & - & - & - \\
\hline Microwave & - & - & - & - & - & 0.0909 & - & 0.1818 & 0.1818 & - & - & - \\
\hline Mixer blender & - & - & - & - & - & - & - & 0.0476 & - & - & - & - \\
\hline Refrigerator & 0.0417 & 0.0417 & 0.0417 & 0.0417 & 0.0417 & 0.0417 & 0.0417 & 0.0417 & 0.0417 & 0.0417 & 0.0417 & 0.0417 \\
\hline Water pump & - & - & - & - & 0.1667 & 0.3333 & - & 0.0833 & 0.0833 & 0.0833 & - & - \\
\hline Washing Machine & - & - & - & - & - & - & - & - & - & 0.0645 & 0.1613 & 0.3226 \\
\hline Cloth Iron & - & - & - & - & - & - & 0.0800 & 0.2000 & 0.1200 & - & - & - \\
\hline Fan & 0.0339 & - & - & - & - & - & - & - & - & - & - & - \\
\hline TV - CRT & - & - & - & - & - & - & - & - & 0.1429 & 0.1429 & - & - \\
\hline TV - LCD & 0.1176 & - & - & - & - & - & - & - & 0.0588 & 0.0588 & 0.0588 & - \\
\hline TV - LED & 0.0250 & - & - & - & 0.0125 & 0.0125 & 0.0375 & 0.0375 & 0.0375 & 0.0125 & 0.0125 & - \\
\hline Desktop & - & - & - & - & - & - & - & - & - & - & - & - \\
\hline Laptop & 0.0357 & 0.0357 & - & - & - & 0.0714 & 0.0714 & 0.0714 & 0.0714 & - & - & - \\
\hline
\end{tabular}

\begin{tabular}{|c|c|c|c|c|c|c|c|c|c|c|c|c|}
\hline & \multicolumn{12}{|c|}{ Time of day } \\
\hline & \multicolumn{12}{|c|}{ PM } \\
\hline & 12 & 1 & 2 & 3 & 4 & 5 & 6 & 7 & 8 & 9 & 10 & 11 \\
\hline LED & - & - & - & - & - & 0.0406 & 0.0576 & 0.1489 & 0.1586 & 0.1824 & 0.1364 & \begin{tabular}{|l|l}
0.0278 \\
\end{tabular} \\
\hline CFL & - & - & - & - & - & 0.0406 & 0.0576 & 0.1489 & 0.1586 & 0.1824 & 0.1364 & 0.0278 \\
\hline TFT & - & - & - & - & - & 0.0406 & 0.0576 & 0.1489 & 0.1586 & 0.1824 & 0.1364 & 0.0278 \\
\hline Bulb & - & - & - & - & - & 0.0406 & 0.0576 & 0.1489 & 0.1586 & 0.1824 & 0.1364 & 0.0278 \\
\hline Rice cooker & - & - & - & - & - & - & - & 0.4000 & 0.1000 & - & - & - \\
\hline Coil heater/hot plate & - & - & - & - & - & - & - & 0.2500 & 0.2500 & - & - & - \\
\hline Induction Cooktop & - & - & - & - & - & - & - & 0.2500 & 0.2500 & - & - & - \\
\hline Microwave & - & - & 0.0909 & - & - & 0.0909 & - & - & 0.1818 & 0.1818 & - & - \\
\hline Mixer blender & - & - & - & - & - & - & 0.1190 & 0.3571 & 0.4762 & - & - & 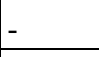 \\
\hline Refrigerator & 0.0417 & 0.0417 & 0.0417 & 0.0417 & 0.0417 & 0.0417 & 0.0417 & 0.0417 & 0.0417 & 0.0417 & 0.0417 & 0.0417 \\
\hline Water pump & - & 0.0833 & 0.0833 & 0.0833 & - & - & - & - & - & - & - & - \\
\hline Washing Machine & 0.3226 & 0.1290 & - & - & - & - & - & - & - & - & - & - \\
\hline Cloth Iron & - & - & - & - & - & - & - & - & 0.2000 & 0.4000 & - & - \\
\hline Fan & - & 0.1017 & 0.1017 & 0.1017 & 0.1017 & 0.1017 & 0.1186 & 0.0847 & 0.0847 & 0.0847 & 0.0847 & - \\
\hline TV - CRT & - & - & 0.1429 & 0.1429 & - & - & - & 0.1429 & 0.1429 & 0.1429 & - & 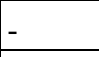 \\
\hline TV - LCD & - & - & - & - & - & - & - & 0.0588 & 0.1765 & 0.1765 & 0.1765 & 0.1176 \\
\hline TV - LED & - & 0.0750 & 0.0750 & 0.0750 & 0.0500 & 0.0625 & 0.0875 & 0.1000 & 0.1000 & 0.1000 & 0.0625 & 0.0250 \\
\hline Desktop & - & - & - & - & - & - & - & 0.1429 & 0.5714 & 0.2857 & - & - \\
\hline Laptop & - & - & \begin{tabular}{|l|l}
0.0179 \\
\end{tabular} & 0.0179 & 0.0179 & 0.0179 & \begin{tabular}{|l}
0.0179 \\
\end{tabular} & 0.1250 & 0.1250 & 0.1250 & 0.1250 & 0.0536 \\
\hline
\end{tabular}


Table 6: Time of use probability profile for household $\mathrm{H}_{3}$

\begin{tabular}{|c|c|c|c|c|c|c|c|c|c|c|c|c|}
\hline & \multicolumn{12}{|c|}{ Time of day } \\
\hline & \multicolumn{12}{|c|}{$\mathbf{A M}$} \\
\hline & 12 & 1 & 2 & 3 & 4 & 5 & 6 & 7 & 8 & 9 & 10 & 11 \\
\hline LED & 0.0052 & 0.0052 & 0.0243 & 0.1231 & 0.1127 & 0.0119 & - & - & - & - & - & - \\
\hline CFL & 0.0052 & 0.0052 & 0.0243 & 0.1231 & 0.1127 & 0.0119 & - & - & - & - & - & - \\
\hline TFT & 0.0052 & 0.0052 & 0.0243 & 0.1231 & 0.1127 & 0.0119 & - & - & - & - & - & - \\
\hline Bulb & 0.0052 & 0.0052 & 0.0243 & 0.1231 & 0.1127 & 0.0119 & - & - & - & - & - & - \\
\hline Rice cooker & - & - & - & - & - & 0.1111 & 0.3333 & 0.0556 & - & - & - & - \\
\hline Coil heater/hot plate & - & - & - & 0.5000 & - & - & - & - & - & - & - & - \\
\hline Induction Cooktop & - & - & - & 0.5000 & - & - & - & - & - & - & - & - \\
\hline Microwave & - & - & - & - & - & - & 0.5000 & - & - & - & - & - \\
\hline Mixer blender & - & - & - & - & - & 0.4615 & 0.1846 & 0.0769 & - & - & - & - \\
\hline Refrigerator & 0.0417 & 0.0417 & 0.0417 & 0.0417 & 0.0417 & 0.0417 & 0.0417 & 0.0417 & 0.0417 & 0.0417 & 0.0417 & 0.0417 \\
\hline Water pump & - & - & 0.1000 & 0.1000 & 0.1000 & 0.1000 & - & - & - & - & 0.1000 & 0.1000 \\
\hline Washing Machine & - & - & - & - & - & - & - & 0.0645 & 0.1613 & 0.3226 & 0.3226 & 0.1290 \\
\hline Cloth Iron & - & - & - & - & 0.0800 & 0.2000 & 0.1200 & - & - & - & - & - \\
\hline Fan & - & - & - & - & - & - & - & - & - & - & - & - \\
\hline TV - CRT & - & - & - & - & - & - & - & - & - & - & 0.2500 & 0.2500 \\
\hline TV - LCD & - & - & - & - & 0.1667 & 0.1667 & - & - & - & - & - & - \\
\hline TV - LED & - & - & - & - & 0.0400 & 0.0400 & 0.0400 & 0.0400 & 0.0600 & 0.0600 & 0.0400 & 0.0400 \\
\hline Desktop & - & 0.0323 & 0.0323 & 0.0323 & 0.0323 & 0.1290 & 0.0968 & 0.0323 & - & - & - & - \\
\hline Laptop & 0.0200 & 0.0200 & 0.0100 & 0.0400 & 0.0800 & 0.0500 & 0.0500 & 0.0400 & - & - & - & - \\
\hline
\end{tabular}

\begin{tabular}{|c|c|c|c|c|c|c|c|c|c|c|c|c|}
\hline & \multicolumn{12}{|c|}{ Time of day } \\
\hline & \multicolumn{12}{|c|}{$\mathbf{P M}$} \\
\hline & 12 & 1 & 2 & 3 & 4 & 5 & 6 & 7 & 8 & 9 & 10 & 11 \\
\hline LED & - & - & - & - & 0.0171 & 0.0965 & 0.1839 & 0.1561 & 0.1130 & 0.0679 & 0.0052 & 0.0052 \\
\hline CFL & - & - & - & - & 0.0171 & 0.0965 & 0.1839 & 0.1561 & 0.1130 & 0.0679 & 0.0052 & 0.0052 \\
\hline TFT & - & - & - & - & 0.0171 & 0.0965 & 0.1839 & 0.1561 & 0.1130 & 0.0679 & 0.0052 & 0.0052 \\
\hline Bulb & - & - & - & - & 0.0171 & 0.0965 & 0.1839 & 0.1561 & 0.1130 & 0.0679 & \begin{tabular}{|l|}
0.0052 \\
\end{tabular} & 0.0052 \\
\hline Rice cooker & - & - & - & - & - & 0.3333 & 0.1111 & 0.0556 & - & - & - & - \\
\hline Coil heater/hot plate & - & - & - & - & - & 0.5000 & - & - & - & - & - & - \\
\hline Induction Cooktop & - & - & - & - & - & 0.5000 & - & - & - & - & - & - \\
\hline Microwave & - & - & - & - & - & 0.5000 & - & - & - & - & - & - \\
\hline Mixer blender & - & - & - & - & - & 0.0769 & 0.2000 & - & - & - & - & - \\
\hline Refrigerator & 0.0417 & 0.0417 & 0.0417 & 0.0417 & 0.0417 & 0.0417 & 0.0417 & 0.0417 & 0.0417 & 0.0417 & 0.0417 & 0.0417 \\
\hline Water pump & 0.1000 & - & 0.1000 & 0.1000 & 0.1000 & - & - & - & - & - & - & - \\
\hline Washing Machine & - & - & - & - & - & - & - & - & - & - & - & - \\
\hline Cloth Iron & - & - & - & - & - & - & 0.2000 & 0.4000 & - & - & - & - \\
\hline Fan & - & - & - & - & - & 0.3333 & 0.3333 & 0.3333 & - & - & - & - \\
\hline TV - CRT & - & - & - & - & - & - & 0.2500 & 0.2500 & - & - & - & - \\
\hline TV - LCD & - & - & - & - & 0.1667 & 0.1667 & 0.1667 & 0.1667 & - & - & - & - \\
\hline TV - LED & 0.0400 & \begin{tabular}{|l|l}
0.0400 \\
\end{tabular} & \begin{tabular}{|l}
0.0400 \\
\end{tabular} & 0.0400 & 0.0600 & 0.0800 & 0.1000 & 0.1000 & 0.1000 & 0.0400 & - & - \\
\hline Desktop & 0.0645 & 0.0645 & 0.0645 & 0.1290 & 0.0645 & 0.0645 & 0.0645 & 0.0323 & 0.0323 & 0.0323 & - & 0.0323 \\
\hline Laptop & - & - & - & 0.0700 & 0.0800 & 0.1000 & 0.1000 & 0.1000 & 0.0900 & 0.0700 & 0.0200 & 0.0200 \\
\hline
\end{tabular}


Table 7: Time of use probability profile for household $\mathrm{H}_{4}$

\begin{tabular}{|c|c|c|c|c|c|c|c|c|c|c|c|c|}
\hline & \multicolumn{12}{|c|}{ Time of day } \\
\hline & \multicolumn{12}{|c|}{$\mathbf{A M}$} \\
\hline & 12 & 1 & 2 & 3 & 4 & 5 & 6 & 7 & 8 & 9 & 10 & 11 \\
\hline LED & 0.0143 & 0.0143 & 0.0074 & 0.0042 & 0.0083 & 0.0693 & 0.0499 & 0.0301 & 0.0030 & 0.0030 & 0.0030 & 0.0030 \\
\hline CFL & 0.0143 & 0.0143 & 0.0074 & 0.0042 & 0.0083 & 0.0693 & 0.0499 & 0.0301 & 0.0030 & 0.0030 & 0.0030 & 0.0030 \\
\hline TFT & 0.0143 & 0.0143 & 0.0074 & 0.0042 & 0.0083 & 0.0693 & 0.0499 & 0.0301 & 0.0030 & 0.0030 & 0.0030 & 0.0030 \\
\hline Bulb & 0.0143 & 0.0143 & 0.0074 & 0.0042 & 0.0083 & 0.0693 & 0.0499 & 0.0301 & 0.0030 & 0.0030 & 0.0030 & 0.0030 \\
\hline Rice cooker & - & - & - & - & - & - & - & 0.2143 & 0.2857 & - & - & - \\
\hline Coil heater/hot plate & - & - & - & - & - & - & - & 0.2500 & 0.2500 & - & - & - \\
\hline Induction Cooktop & - & - & - & - & - & - & - & 0.2500 & 0.2500 & - & - & - \\
\hline Microwave & - & - & - & - & - & 0.0909 & - & 0.1818 & 0.1818 & - & - & - \\
\hline Mixer blender & - & - & - & - & - & - & - & 0.4615 & 0.1846 & 0.0769 & - & - \\
\hline Refrigerator & 0.0417 & 0.0417 & 0.0417 & 0.0417 & 0.0417 & 0.0417 & 0.0417 & 0.0417 & 0.0417 & 0.0417 & 0.0417 & 0.0417 \\
\hline Water pump & - & - & - & 0.0645 & - & 0.1290 & 0.2581 & 0.0323 & 0.0968 & 0.0323 & - & - \\
\hline Washing Machine & - & - & - & - & - & - & - & - & - & 0.0645 & 0.1613 & 0.3226 \\
\hline Cloth Iron & - & - & - & - & - & - & - & 0.4286 & 0.4286 & 0.1429 & - & - \\
\hline Fan & 0.0206 & - & - & - & - & - & - & - & - & - & - & - \\
\hline TV - CRT & - & - & - & - & - & - & - & - & 0.1429 & 0.1429 & - & - \\
\hline TV - LCD & 0.0345 & - & - & - & - & - & - & 0.0690 & 0.0690 & 0.0690 & 0.0690 & 0.0345 \\
\hline TV - LED & 0.0210 & - & - & - & - & 0.0210 & 0.0378 & 0.0462 & 0.0546 & 0.0420 & 0.0210 & 0.0168 \\
\hline Desktop & - & - & - & - & - & 0.0278 & 0.0278 & 0.0278 & 0.0278 & 0.0556 & 0.0556 & - \\
\hline Laptop & 0.0667 & 0.0667 & 0.0242 & - & - & 0.0121 & 0.0303 & 0.0424 & 0.0364 & 0.0242 & 0.0303 & 0.0182 \\
\hline
\end{tabular}

\begin{tabular}{|c|c|c|c|c|c|c|c|c|c|c|c|c|}
\hline & \multicolumn{12}{|c|}{ Time of day } \\
\hline & \multicolumn{12}{|c|}{ PM } \\
\hline & 12 & 1 & 2 & 3 & 4 & 5 & 6 & 7 & 8 & 9 & 10 & 11 \\
\hline LED & 0.0030 & 0.0030 & 0.0030 & 0.0030 & 0.0030 & 0.0030 & 0.0369 & 0.1986 & 0.1859 & 0.1836 & 0.1073 & 0.0601 \\
\hline CFL & 0.0030 & 0.0030 & 0.0030 & 0.0030 & 0.0030 & 0.0030 & 0.0369 & 0.1986 & 0.1859 & 0.1836 & 0.1073 & 0.0601 \\
\hline TFT & 0.0030 & 0.0030 & 0.0030 & 0.0030 & 0.0030 & 0.0030 & 0.0369 & 0.1986 & 0.1859 & 0.1836 & 0.1073 & 0.0601 \\
\hline Bulb & 0.0030 & 0.0030 & 0.0030 & 0.0030 & 0.0030 & 0.0030 & 0.0369 & 0.1986 & 0.1859 & 0.1836 & 0.1073 & 0.0601 \\
\hline Rice cooker & - & - & - & - & - & - & - & 0.3214 & 0.1786 & - & - & - \\
\hline Coil heater/hot plate & - & - & - & - & - & - & - & 0.2500 & 0.2500 & - & - & - \\
\hline Induction Cooktop & - & - & - & - & - & - & - & 0.2500 & 0.2500 & - & - & - \\
\hline Microwave & - & - & 0.0909 & - & - & 0.0909 & - & - & 0.1818 & 0.1818 & - & - \\
\hline Mixer blender & - & - & - & - & - & - & - & 0.0769 & 0.2000 & - & - & - \\
\hline Refrigerator & 0.0417 & 0.0417 & 0.0417 & 0.0417 & 0.0417 & 0.0417 & 0.0417 & 0.0417 & 0.0417 & 0.0417 & 0.0417 & 0.0417 \\
\hline Water pump & 0.0323 & 0.0323 & 0.0323 & - & - & 0.0645 & 0.2258 & - & - & - & - & - \\
\hline Washing Machine & 0.3226 & 0.1290 & - & - & - & - & - & - & - & - & - & - \\
\hline Cloth Iron & - & - & - & - & - & - & - & - & - & - & - & - \\
\hline Fan & 0.0206 & 0.0825 & 0.1134 & 0.1134 & 0.0928 & 0.0825 & 0.0928 & 0.0928 & 0.1031 & 0.0825 & 0.0825 & 0.0206 \\
\hline TV - CRT & - & - & 0.1429 & 0.1429 & - & - & - & 0.1429 & 0.1429 & 0.1429 & - & - \\
\hline TV - LCD & - & 0.0345 & 0.0345 & 0.0345 & 0.0345 & 0.0690 & 0.0862 & 0.0862 & 0.0862 & 0.0862 & 0.0690 & 0.0345 \\
\hline TV - LED & 0.0294 & 0.0672 & 0.0714 & 0.0588 & 0.0462 & 0.0420 & 0.0546 & 0.0840 & 0.0924 & 0.1008 & 0.0630 & 0.0294 \\
\hline Desktop & - & - & - & 0.0278 & 0.0278 & 0.0833 & 0.0833 & 0.1111 & 0.1389 & 0.1389 & \begin{tabular}{|l|l|}
0.1389 \\
\end{tabular} & 0.0278 \\
\hline Laptop & 0.0121 & 0.0242 & 0.0121 & - & - & - & 0.0364 & 0.0909 & 0.1091 & 0.1273 & \begin{tabular}{|l}
0.1273 \\
\end{tabular} & \begin{tabular}{|l}
0.1091 \\
\end{tabular} \\
\hline
\end{tabular}

